\title{
DESENVOLVIMENTO RURAL E BIOPODER: reflexões a partir do campo tecnocientífico
}

\author{
Adriano Premebida* \\ Jalcione Almeida*
}

Resumo: Este artigo analisa discursos acerca do desenvolvimento rural e sua aproximação com um particular entendimento de exercício de poder, com base em entrevistas realizadas com agentes do denominado campo tecnocientífico vinculado às ciências agrárias no sul do Brasil. O espaço de encontro entre uma configuração teórica associada a uma analítica do poder e a regularidade dos discursos sobre desenvolvimento rural leva à suposição de que este espaço comum de produção de sentido e sustentação discursiva está intimamente ligado a uma ampla estratégia econômica e política (própria ao capitalismo) de gestão de populações (lógica da inclusão), de aplicação de dispositivos e tecnologias variadas de acordo - e no limite - com a perspectiva do biopoder. Para inferir esta relação, tenta-se utilizar o referencial teórico da análise de discurso mediante seu método mais simples: o exame da constância de repetição de termos-chave pelos agentes em suas exposições sobre o debate atual do desenvolvimento rural. Este referencial ajuda a entender a concepção de um indivíduo coerente e consciente de seu discurso, bem como a perceber a persistência ou modificação de certas crenças e mitos na formação de ideais societários para o rural no Brasil.

\footnotetext{
* Mestre em Desenvolvimento Rural, doutorando no Programa de Pós-Graduação em Sociologia da Universidade Federal do Rio Grande do Sul (UFRGS). E-mail: premebida@hotmail.com .

**Doutor em Sociologia, professor e pesquisador dos programas de pós-graduação em Desenvolvimento Rural e em Sociologia, ambos da UFRGS. Pesquisador do CNPq. Email: jal@ufrgs.br.
}

Os pesquisadores pertencem ao grupo de pesquisa Tecnologia, Meio Ambiente e Sociedade (TEMAS/UFRGS).

Artigo recebido em 2 set. 2005; aprovado em 17 maio 2006. 
Palavras-chave: desenvolvimento rural, campo tecnocientífico, biopoder.

\section{Sobre a noção de desenvolvimento rural}

O desenvolvimento rural (DR) é uma noção que se apresenta com diferentes e sedutores significados (Rist, 1996). Apesar dos significados de DR, como também de noções outras que o cercam estarem por vezes em divergência conceitual, existe um espaço comum, uma memória, por onde se constitui uma regularidade discursiva (Maingueneau, 1989). E é da discussão teórica de algumas idéias sobre estratégias de intervenção social expressas nessa regularidade discursiva que trata este artigo, mediante entrevistas realizadas com agentes do aqui denominado campo tecnocientífico. Uma regularidade, no entanto, obtida mais por efeito de uma abordagem teórica do que por uma manifestação presumida e natural desses discursos sobre DR. O espaço de encontro entre a configuração teórica usada neste trabalho e a regularidade dos discursos sobre DR leva à hipótese de que o espaço comum (de produção de sentido) que sustenta esses discursos pode estar intimamente ligado a uma ampla estratégia econômica e política de gestão de populações (lógica da inclusão), de aplicação de dispositivos e tecnologias variadas de acordo com a perspectiva do biopoder - e no seu limite - sendo este um "elemento indispensável ao desenvolvimento do capitalismo, que só pôde ser garantido à custa da inserção controlada dos corpos no aparelho de produção e por meio de um ajustamento dos fenômenos de população aos processos econômicos" (Foucault, 1999, p. 132).

Esta proposição toma forma à medida que se tenta verificar se nas falas sobre DR há a idéia de que o desenvolvimento se materializa tendo por base um conjunto de ações e conseqüências visando, principalmente, à construção de espaços de liberdade, de saúde, de capacitação econômica e participação política para as populações rurais. E é por meio desses espaços que também atuam relações de poder instituindo positividades mediante práticas, sujeitos e saberes. As noções de desenvolvimento e biopoder, então, se concatenam na 
análise conforme os sentidos dessa encruzilhada vão se referindo às populações, ao seu bem-estar, às suas práticas, às regulações territoriais. Embora quatro grandes temas tenham conduzido as entrevistas desta pesquisa (trajetória social, problemática ambiental, ciências agrárias e desenvolvimento rural), somente o último é aqui analisado com maior profundidade, ainda que todos estivessem, quase sempre, relacionados entre si.

O desenvolvimento rural expressa um ideal no qual se enraízam representações referentes a planejar, pensar, adaptar ou transformar uma determinada realidade. $\mathrm{O}$ posicionamento frente a esta noção torna-se, então, extremamente delicado, justamente por estar na fronteira entre produzir um conhecimento crítico sobre o rural e suas derivações sociais, e assumir posicionamentos acerca de programas de intervenção nessa realidade. Ficar no limiar dos campos político e científico implica consciência disso; joga-se em campos diferentes com regras, articulações discursivas e motivações diferentes que, por vezes, não se tangenciam. Se a tomada de decisões relativas à implementação de ações visando ao desenvolvimento, a quem ou ao que se aplica é estar mais ou menos preso às regras das forças motivadoras de instauração de um mundo da política e suas expressões de poder, isso pressupõe um jogo entre esses dois campos.

A noção de DR relaciona-se, em suas mais variadas expressões, com noções ainda mais amplas (como progresso, crescimento), constituindo um sistema de idéias e representações de sociedade. A sustentação de um sistema simbólico por grupos de interesse busca estipular, por exemplo, práticas pedagógicas, domínio hierárquico e a instituição de saberes através da criação de um relativo consenso social. Pensando em uma mediação técnica e/ou social que diz respeito a um investimento em determinada noção de DR - sempre compartimentada em uma posição frente a tantas outras visões de mundo em jogo, expressas e referendadas nos discursos - sua possibilidade de crédito estará dependente de um compartilhamento, pela população-alvo, do sistema simbólico que estrutura sua lógica e representação. Supondo vários sistemas 
simbólicos ou ideológicos disponíveis na sociedade contemporânea, a escolha de um deles ou, dependendo das circunstâncias de vida, de mais de um, mesmo excludentes, não é claramente ou totalmente consciente, refletido e voluntário, mas dependente, em maior ou menor grau, da posição, convergência e origem de classe, tanto da discursividade preponderante e legítima do campo como do agente. É válido ressaltar que os sistemas simbólicos não são apenas entidades organizativas dos seres no mundo, institucionalizados ou não, e passivamente abertos a escolhas pessoais. Mantêm-se ligados a um contexto histórico de origem e a grupamentos sociais com maior acesso às interpretações de suas codificações. Os sistemas simbólicos fundam ou, pelo menos, condicionam os sujeitos, suas representações, seus discursos, articulando uma rede complexa de representação de si, dos outros e das coisas (Bourdieu, 1974).

A elaboração de um projeto de DR dificilmente se faz com homogeneidade, porque ele abrange diferentes mundos e interesses, os quais se interpenetram, se misturam e entram em conflito; é uma tentativa de união de vários projetos individuais, que se caracterizam por códigos de emoções e percepções, esquemas simbólicos e interesses múltiplos relativos à classe social, ao grupo étnico e à filiação partidária. Projetos sociais são expressões simbólicas referentes à estruturação, à organização e às mudanças de espaços sociais, como vizinhança, cooperativa, bairro, trabalho, família, envolvidos por relações de poder e roteiros políticos (Velho, 1999). Projetos sociais implicam a manipulação de instrumental simbólico - como linguagem e capitais variados -, que os grupos (em relação à sua posição e trajetória perante o resto da sociedade) utilizam como recurso para a veiculação de seus interesses.

\section{O discurso e a prática no campo tecnocientífico}

O denominado campo tecnocientífico foi o lugar demarcado para o levantamento das possibilidades de significado do desenvolvimento rural entre os agentes entrevistados. Um campo é um espaço de significados e é condicionado e envolvido por posições 
relativas entre os agentes, posições formadas historicamente em meio a contendas sobre visões de mundo. Apesar de se caracterizar inicialmente um campo com fronteiras, estas não são fixas, pois funcionam por intermédio de modulações. Há uma variação de suas extensões e limites segundo outras instâncias que o tangenciam: a política, a social, a religiosa e a econômica, entre outros espaços sociais, que se autodeterminaram como campos autônomos de ações de interesse coletivo na sociedade moderna ocidental (Bourdieu, 1983).

O uso do conceito de tecnociência foi uma maneira de mostrar o espaço e o traçado da lógica de criação e reprodução de um conhecimento diluído em historicidade, onde estão inseridos, direta ou indiretamente, os agentes entrevistados. Levando em conta que esse termo denota uma produção científica dirigida e voltada para e pela tecnologia moderna e orquestrada pelo capitalismo, fica ainda um ponto: alguns dos agentes entrevistados, por razões disciplinares ou área de formação acadêmica, não necessariamente produzem conhecimento ligado a algum tipo direto de atividade tecnológica, mas entendem o desenvolvimento como processo indissociável do uso e expansão da tecnologia e, por intermédio da extensão rural, divulgam novas tecnologias.

Para a análise das falas dos agentes no campo estudado foi necessário situar e desdobrar alguns pressupostos teóricos da produção discursiva acerca do DR. Mesmo existindo uma abertura para a emergência de novas maneiras de dizer, de novas condições para pensar a sociedade, os agentes sociais não se organizam nem se exprimem como querem. Eles geralmente agem, reagem, avaliam, julgam, criticam, censuram como membros posicionados e produzidos por relações sociais mais ou menos conflituosas. Os discursos cruzam-se a todo o momento, estabelecendo relações históricas de aproximação e distanciamento, aglutinando-se e apoiando-se mutuamente no estabelecimento de afinidades de persuasão e justificativas (Pêcheux, 1997). Os grupos sociais em conflito ou em acordo estabelecem, mediante discursos, a garantia da instituição e legitimidade do dizível com base em suas visões 
de mundo. Suas falas e textos remetem sempre a discursos que, na comunicação, materializam suas experiências e interações sociais (Gnerre, 1991).

As relações formadas em campos específicos da sociedade estão matizadas pelas interações dos grupos sociais em seu seio, e estes se estruturam pela incorporação do seu passado comum, dirigidos por categorias específicas de tempo, espaço, formulações axiológicas, causalidades que enfeixam e situam, razoavelmente, a multiplicidade de obstáculos de suas existências. A despeito de uma autonomia do campo tecnocientífico, este não está livre da inserção, em sua área de atuação, de múltiplos conflitos acerca de categorias e conceitos que afetam, direta ou indiretamente, a vasta região do plano social e político. Estas categorias e conceitos ligados às condições sociais de elaboração por grupos parciais e influenciados por orientações específicas de valores, são, na maior parte das vezes -, tendo em vista a própria especificidade do campo tecnocientífico -, transmitidos em esquemas universais de equivalência e competência.

Como em qualquer campo, no tecnocientífico os agentes possuem capitais específicos adquiridos de forma variável, como variável é uma trajetória social (Bourdieu, 1983). Para ser apreendida, reproduzida e usada eficazmente, a produção disponibilizada no campo precisa de uma chave de abertura, ou seja, necessita de capital específico ligado à produção do trabalho científico. Nas lutas particulares por cooptação e distanciamento das posições objetivas dos agentes, no jogo da ciência validada como oficial (na tradição kuhniana, alguns diriam "normal"), existe um fluxo de formações ideológicas que tomam parte neste jogo. O principal objetivo dessa concorrência é universalizar e convencionalizar particularidades teóricas compreensíveis e inteligíveis aos agentes que objetivaram a ciência e a tecnologia enquanto estados particulares universalizados. Mesmo interesses particulares estando de certo modo nas prioridades do jogo dos agentes da ciência (e, nesse caso, nas definições de DR), 
por vezes, e dependendo do ponto de vista, o exercício de discussão resultante desse jogo torna-se proveitoso tanto para os dominantes como para os dominados de uma sociedade, reforçando posturas críticas frente a preconceitos de autoridade e possibilitando modelos de ação política e tecnológica que beneficiam grande parcela da população.

\section{Procedimentos metodológicos da pesquisa}

Quais as bases discursivas que sustentam os significados ou sentidos da noção expressa por agentes do campo tecnocientífico na Região Sul do Brasil? A opção de formulação dos sentidos da noção de DR recaiu sobre um conjunto de instituições e agentes nos Estados dessa região vinculado às ciências agrárias, desde universidades até órgãos de pesquisa e extensão rural, públicos e/ou privados, governamentais ou não-governamentais. Após o planejamento do roteiro das entrevistas, passou-se à escolha das instituições. Nas instituições de ensino com algum curso dentro do rol das ciências agrárias, optou-se pelas que tivessem a pesquisa como componente de sua prática.

Selecionadas as instituições, foi preciso escolher nomes que iriam compor o universo dos agentes de cada instituição, escolhidos principalmente pela Internet (páginas eletrônicas das respectivas instituições com a listagem do quadro de profissionais). Os nomes foram sorteados e postos em uma ordem. Caso um agente escolhido, por um motivo qualquer, não pudesse realizar a entrevista, passar-seia ao agente seguinte na ordem do sorteio. Este seria o procedimento até as entrevistas atingirem um ponto de saturação, que, em síntese, ocorre a partir de um certo número de entrevistas coletadas, as posteriores não acrescentando praticamente nada ao que as outras têm expressado (Marre, 1991; Flick, 2004).

No afã de perceber polaridades, geralmente era solicitado aos agentes entrevistados nomes de pares com opinião contrária ou discordante. Ainda assim, como a pesquisa ficou centrada apenas 
nas questões relativas ao DR, o tom dos discursos, até pelo tipo de perspectiva teórica desta pesquisa, permaneceu relativamente regular.

As entrevistas (no total de 25) foram realizadas em:

a) Instituições de ensino e pesquisa: Universidade Federal do Paraná (UFPR); Universidade Federal de Pelotas (UFPel); Universidade Federal do Rio Grande do Sul (UFRGS); Universidade Federal de Santa Catarina (UFSC); Universidade Federal de Santa Maria (UFSM).

b) Instituições de pesquisa e/ou extensão (governamentais e não-governamentais): Centro Ecológico Ipê (CE-Ipê); Empresa Brasileira de Pesquisa Agropecuária (EMBRAPA Trigo) em Passo Fundo e EMBRAPA Clima Temperado, Estação Experimental Cascata em Pelotas; Empresa Paranaense de Assistência Técnica e Extensão Rural (EMATER - Paraná); Empresa de Assistência Técnica e Extensão Rural (EMATER - Rio Grande do Sul); Instituto Agronômico do Paraná (IAPAR); Rede de Articulação de Setores Rurais de Santa Catarina (AGROREDE).

O referencial teórico escolhido e apoiado sobre noções e procedimentos de análise do discurso considera duas questões como básicas na sua aplicação como método: a) questionar uma concepção idealista de sujeito posto como totalmente livre, e conduzindo o processo de produção de sentido segundo o reflexo de uma realidade preexistente "não-teorizada"; b) assumir uma postura crítica diante dos dados ditos literais e límpidos, patentes, que os sujeitos utilizam por meio da linguagem, como se fossem exteriores a um projeto teórico. Assim, há um conjunto de pressuposições frente à abordagem que se fará acerca do tema do desenvolvimento rural. Talvez a mais importante seja a de que um certo número de regras sociais e políticas delimita as condições de possibilidades das falas sobre desenvolvimento ou DR, ajustadas a certos critérios de organização de uma sociedade ou de um campo específico de poder. 
O termo discurso apresenta muitos significados, geralmente associados à transmissão de informações apenas, dita função cognitiva ou denotativa, tendo a língua como finalidade comunicar informações. Essa perspectiva denotativa tende a encarecer a função discursiva como um raciocínio que segue um percurso, atingindo os objetivos propostos da comunicação de informações entre emissor e receptor em sua extensão até alcançar um ápice relativamente conclusivo. Entende-se por discurso nesta pesquisa um processo de produção de sentido dentro de um contexto sociocultural e que se utiliza de códigos (funções da linguagem), com seus efeitos sobre sujeitos em interação. Os sujeitos são constituídos e identificados no funcionamento discursivo via materialidade lingüística e histórica, ambas carregando consigo posições de classe, esquemas de percepção e construção de realidade manifestas na interação comunicativa. O discurso é considerado o lugar de constituição dos sentidos pressupostos nas visões de mundo dos sujeitos locutores. É uma inscrição de representações da realidade e formas de subjetivação nas relações semânticas reveladas nos discursos (Orlandi, 2004).

A implicação construtivista da noção de discurso conjectura a prática discursiva construindo "tipos sociais", sujeitos posicionados em um sistema classificatório nos variados quadrantes de uma formação social e, através do discurso e das práticas nãodiscursivas, identificando tanto o indivíduo como o outro nas relações interpessoais. Todo este aparato relacional, classificatório e identificatório está dirigido por um sistema de conhecimento e crença construído pelo exercício discursivo encontrado nos textos e nas falas, sistema fundante de significados, em seu seguimento temporal e espacial, em seu conjunto ordenado de seres, com suas correspondências entre grandezas, hierarquias e conexões de causa e efeito. $\mathrm{O}$ contato estabelecido na interação discursiva organiza e afirma as posições sociais dos sujeitos, estabelecendo negociações entre as maneiras de se dar as relações sociais entre os locutores (Bourdieu, 1974) . 
O discurso funciona como uma ação nominal, estando montada sobre uma estrutura política, cultural, econômica e técnica de extensão histórica, ou seja, uma nominação estruturada e estruturante de acordo com as relações concretas de divisão do modo de produção, das relações de gênero, dos comportamentos emocionais culturalmente condicionados, dos projetos, leis, doutrinas, dogmas, costumes, enfim, da coexistência humana. Essa perspectiva situa-se como ponto de vista crítico a uma idéia de consciência soberana, livre na fundação das relações de significado. O discurso, enquanto prática política e ideológica, textualiza modos de relações entre sujeitos e entre grupos, classes, comunidades, partidos, entre os quais existem necessariamente relações de poder.

\section{A formação do corpus}

Sendo termo técnico de uso na lingüística, de modo simplificado e um tanto adaptado a pesquisas nas ciências sociais e humanas fora do estrito campo lingüístico, corpus é a constituição de um conjunto de enunciados, após passar por critérios de análise e seleção arbitrárias de um "universo" (ou corpus empírico) de enunciados possíveis ou dados em determinada circunstância histórica e social (Bauer; Aarts, 2002). Do "universo" para o corpus (ou corpus discursivo), os enunciados passam pelo crivo de uma análise mais rigorosa. No caso, o campo discursivo de referência, e do qual se constrói o corpus, é a totalidade dos discursos dos agentes do campo tecnocientífico. Assim, grande parte dos enunciados produzidos pelos entrevistados não foi usada na pesquisa: a) ou por não terem relação com o recorte temático especificado na pesquisa; ou b) porque certos enunciados com relações interessantes e pertinentes não foram percebidos pelo pesquisador; ou, c) ainda, porque certas associações não poderiam ser analisadas e comentadas dentro do tempo hábil de produção da pesquisa.

A seleção e a constituição do corpus da pesquisa já envolvem um comprometimento com um tipo de análise de discurso, pois 
analisar implica já estar ciente do que pertence ou não a um corpus. Ao selecionar material discursivo sobre desenvolvimento ou DR, abriuse um quadro de relações entre a tendência de práticas de biopoder estar presente na constituição do discurso sobre desenvolvimento e, conseqüentemente, sobre DR.

Ao notar que o discurso sobre as noções de DR se pauta pela polêmica, ou seja, fundamenta-se por uma polissemia controlada (Orlandi, 2002) - os interlocutores não abrindo ou fechando demais suas margens de definição -, procurou-se perceber como o referente discursivo era direcionado pelos agentes. O corpus formado pelas falas sobre DR não está amparado por discursos tão-somente homogêneos e coerentes com o que se espera de uma retórica científica. O corpus está cortado, também, por discursos de outras áreas, de outros campos, como o político, formando um todo intrincado, com muitas convergências interpretativas, como a tendência de usar uma noção de natureza para justificar determinadas posições morais ou políticas ou realçar bucolicamente a inocência, como, por exemplo, na seguinte fala:

“eu considero que o meio rural tem uma vida saudável, ele precisa... poucas coisas para ele ficar bom mesmo. Ele precisa ter saúde, escolas e, principalmente, acho que cooperativas que protejam o meio rural da exploração do meio urbano" (Professor 1, Agrônomo, 63 anos, UFRGS).

De modo geral, o discurso da saúde, quando posto lado a lado à noção de $\mathrm{DR}$, apareceu não exclusivamente como uma política particular para assistir a população com pouco acesso ao sistema de saúde pública. Seu sentido oferece uma variedade de interpretações, pois o tema da saúde, além de abarcar direta ou indiretamente diversas situações e objetos, tende a ser expresso pela condição social do entrevistado, por exemplo, a saúde como modo de ser, tendo em vista que o

"DR não passa apenas dentro da porteira, o DR tem que ser algo ligado ao desenvolvimento do todo, à qualidade do alimento [...] dentro dos centros urbanos, as pessoas precisam saber o que 
consumir, e o equilíbrio entre o que consumir" (Professora 2, Médica Veterinária, 49 anos, UFRGS).

Tentou-se constituir o corpus por posições políticas e teóricas diferenciadas entre os entrevistados, para assim dar ocasião a comparações entre noções de DR. Nesta tentativa de analisar posições contrárias, percebeu-se que as opiniões e definições sobre DR ficaram num patamar conceitual comum relacionado ao bemestar das populações rurais, principalmente quanto à questão do uso de novas tecnologias na produção agrícola como causa indireta desse bem-estar (aumento da renda dos agricultores, que formam parcela considerável das populações rurais). Em muitos casos, estas noções se definiam ou se esclareciam favoravelmente ou em oposição a um conjunto de ações e idéias ligadas ao "crescimento econômico" e à “implementação das novas técnicas de mecanização na agricultura". Esta divisão de opiniões segue uma trajetória histórica de debates (desde a década de 1970) sobre tecnologias produtivas na agricultura brasileira (Almeida, 1989; 1999), mas os argumentos usados a favor ou contra certa noção de DR são majoritariamente os mesmos, e é a isso o que aqui se chama patamar conceitual comum. A produção de sentido dos discursos sobre DR se fez, portanto, sobre uma base discursiva maior, muito próxima à noção de biopoder, no que atinge determinações históricas de processos semânticos e técnicos sobre o controle do corpo, da vida e da sociedade com todas as condições de produção de uma formação discursiva.

\section{Biopoder e desenvolvimento rural: expansão de um novo modelo de intervenção}

Certos temas foram muito comuns nas entrevistas, verdadeiros eixos sobre os quais gravitaram as discussões relativas à noção de desenvolvimento ou desenvolvimento rural, formando, assim, um patamar conceitual comum pelo qual segue agora a análise das proposições observadas nas entrevistas. $\mathrm{O}$ cruzamento desses temas, palavras-chave regulares e usuais, forma o espaço discursivo do qual emerge toda a vitalidade da noção de DR. Esta noção foi 
expressa dentro de um quadro de mitos e crenças estruturantes dos parâmetros civilizatórios hegemônicos do ocidente: a abundância e a previdência acenadas pela ciência, por exemplo, frente a um mundo contingente; a luta contra as causas da mortalidade, a carência material e a narrativa ligada aos ideais de progresso e de desenvolvimento tecnológico.

A sofisticada estrutura de poder que envolve a sociedade capitalista contemporânea apresenta um constante aperfeiçoamento da organização da vida social através de técnicas de poder que incidem sobre os "corpos em multidão" e na vastidão territorial, caracterizadas por Foucault (2002) como biopolítica (enquanto força que regula populações), contrário da disciplina (enquanto força, treinamento, realizado no corpo individual, no espaço fechado), não obstante uma e outra se complementarem. A norma é o que liga uma técnica e outra de poder, caracterizando, assim, o biopoder. A atuação do poder sobre os corpos é representada por dois esquemas ou exercícios interdependentes: o primeiro, referese ao poder disciplinar, ao treinamento "ortopédico" dos corpos, os "métodos que permitem o controle minucioso das operações do corpo, que realizam a sujeição constante de suas forças e lhes impõe uma relação de docilidade-utilidade" (Foucault, 1977, p. 126); o segundo, é relativo ao poder exercido sobre as populações, com sua variante de regularidades e todo o conjunto de discursos que lhe concerne. $\mathrm{O}$ aparato científico ajustado a essa lógica estabelece uma gestão e controle mais efetivo de uma população, procurando atuar intensivamente em todas as áreas sociais de acordo e em parte com um discurso do desenvolvimento.

Se as noções de DR expressas nas entrevistas têm muitos elementos propositivos representados na idéia de biopoder, é de se considerar, criticamente, a aproximação das políticas de desenvolvimento com um padrão de justificação e ação do sistema capitalista. Esse padrão não é universal no tempo e no espaço, variando segundo certas especificidades históricas de enfrentamentos políticos e sociais, tendo seu exemplo bem acabado nas políticas de bemestar social promovidas em alguns países, sobretudo os europeus. 
Ao mesmo tempo em que buscam, de acordo com as entrevistas, a "emancipação", a "liberdade", a "vida boa" - expressões geralmente neutralizadas quanto ao quesito das relações de poder -, as políticas de desenvolvimento tendem a agir nos variados níveis do cotidiano individual, conduzindo processos de subjetivação e socialização, provocando ou oprimindo desejos e necessidades, em graus variados de sutileza e normalização. Mas as ações de desenvolvimento não são forças determinantes e unilaterais, controlando e cooptando desejos e sonhos, impondo deveres, obrigações, regras de conduta, proibições, contratos; são situações tomando forma e sendo negociadas em função das relações de forças presentes em dado momento histórico.

Seria cinismo, contudo, interceder contra qualquer idéia de desenvolvimento em um país com grande parte da população exposta à indigência. A crítica neste trabalho tende a incidir sobre os usos da noção de desenvolvimento como panacéia aos grandes problemas enredados na discussão pública (e idealmente pensados como livres de relações de poder e, por vezes, de dominação), como desemprego e destruição ambiental, ou sobre a idéia de desenvolvimento como sinônimo de emancipação social desvinculada de sistemas de controle produzidos na sociedade capitalista (Almeida, 1999). Fica então a posição teórica, um tanto programática, de pensar o DR como expressão que, muitas vezes, encabeça todo um discurso e prática social não-discursiva, funcionando na propagação, justificação e intensificação de novas formas de relações de dominação nas sociedades contemporâneas.

Muito se pode pensar que dar existência a uma sociedade desenvolvida mais é elaborar, aparentemente, uma economia social de normalização do que se furta a um sistema de classificação, do que se extravia do registro e vigilância governamentais e padrões hegemônicos de interação econômica e sociocultural. Seguindo essa perspectiva, então, a pobreza, por exemplo, toma forma de algo preocupante à atividade produtiva de uma sociedade. Tenta-se alijar ao máximo suas conseqüências negativas para a sociedade, algo possível ao demarcar a população, os indivíduos, de modo 
utilitário. Ao centrar a necessidade da produção, da saúde e a idéia de bem-estar físico e moral, novas formas de governo passam a se preocupar com o ordenamento da população, com a utilidade dos indivíduos, com formas de gestão entre comportamento populacional, posicionamentos políticos e, atualmente, suas relações com questões ambientais: "um homem estando bem, ele vai ter um comportamento adequado, no solo, na água" (Professor 3, Agrônomo, 43 anos, UFSC). A questão ambiental torna-se um meio pelo qual transitam diversas posições sobre formas de regulação da produção material e imaterial das sociedades contemporâneas.

As políticas de desenvolvimento e suas relações com dispositivos de planejamento e controle situam-se, nas sociedades capitalistas, em um espaço discursivo comum, afeitos a um sentido de governo auxiliado por novas tecnologias e saberes na função de gerir a vida biológica dos indivíduos e das populações. Instituições lançam mão do exame dos movimentos próprios da vida humana, buscando a minúcia de todos os seus aspectos. Pensando principalmente no modelo clássico de extensão rural - com seu conjunto de questionários, exames e difusão de saberes e técnicas -, normas de socialização das sociedades avançadas, tecnificadas, informatizadas, "em rede", visam integrar todos os aspectos de práticas sociais não cooptadas ou micropráticas não colonizadas por uma "cultura hegemônica". Diversas experiências isoladas são recortadas e anexadas em domínios apropriados de estudos teóricos e de intervenção socioeconômica. Definem-se os padrões de funcionamento de certas práticas, difundem-se esquemas de ação, discursos, idéias e ideais identificados a um padrão civilizatório, de desenvolvimento, a uma normalidade e, após esse processo, identificam-se o diferente, a anomalia e a exceção para tratá-los e reintegrá-los às práticas normalizadoras segundo uma estratégia discursiva de justificação e legitimação de sociedade.

\section{Engajamento e controle na dispersão}

A narrativa caracterizadora da noção de desenvolvimento segue a indicação da formação e "capacitação permanente" a um 
devir; não se termina o que se começa, modificam-se parâmetros continuamente (Deleuze, 1992) "para as gerações futuras", para a "preservação do ambiente", dos ideais de consumo e produção, do certo e errado, como produzir e o que produzir. Forma-se, então, um novo sistema de engajamento subjetivo nas sociedades capitalistas, uma tensão entre possibilidades de controle e emancipação. E o que tende a caracterizar os novos arranjos da sociedade capitalista atual, em sua estratégia operacional nas políticas de DR no Brasil e outros lugares, é toda uma série de operações tecnológicas, informatizadas, precisando as informações de relatório e controle. Nas entrevistas, os avanços tecnológicos quase que invariavelmente estavam conectados à órbita discursiva acerca do DR ou do desenvolvimento, tanto às posições dos agentes com perspectiva mais modernizante de sociedade, principalmente ao modo de produção agrícola, quanto das mais alternativas, que punham em questão os propalados benefícios das novas tecnologias na agricultura, que direta ou indiretamente afetam o mundo rural:

"A própria ciência, a própria tecnologia, elas nos levam a descobrir outras ações que têm que ser implementadas junto com o agricultor" (Extensionista 1, Agrônoma, 34 anos, EMATER-PR).

As novas tecnologias, na medida em que recrudescem sistemas de controle, podem, por outro lado, abrir espaços para novas possibilidades de emancipação e interação. Novos conhecimentos e tecnologias produzem formas inovadoras de produção, articulandoas, mediante um complexo circuito, a sistemas de identidade e consumo (consumidores de produtos ditos orgânicos, por exemplo), tanto localmente (feiras de produtores locais) como globalmente (produção de commodities agrícolas).

Neste processo aberto pelas novas tecnologias do conforto doméstico, da energia elétrica, das telecomunicações, "o desenvolvimento rural é um resultado de ações onde a visão atual que se tem é de que, em primeiro lugar, a família se sinta bem, viva bem" (Extensionista 2, Engenheira Agrícola, 41 anos, EMATERPR), e isso supõe um engajamento subjetivo, uma demanda entre os 
sujeitos desse espaço e os discursos que transitam em um sistema capitalista hegemônico. Além disto, observa-se que a família como instituição social (como percebido pelo constante uso da categoria agricultura familiar em políticas de desenvolvimento, por exemplo) ainda é considerada como unidade básica de intervenção em políticas cujas ações operam resultados no conjunto populacional.

Nas entrevistas revelou-se patente a percepção sobre o quesito de integração das populações rurais a novas formas de interação social e cultural promovidas pelo capitalismo, tanto nas posturas críticas a este respeito, quanto nos enaltecimentos dessa integração. E um dos mais importantes elos para a passagem de relações sociais tradicionais no mundo rural para relações tidas como modernas ou capitalistas foram as novas possibilidades de produção postas pelo aparato tecnológico contemporâneo.

Apreensão da subjetividade ou outros modos de ação do desenvolvimento

Se o DR, enquanto espaço discursivo orientado por projetos de ação política no "cumprimento das demandas das populações rurais", foi uma tendência preponderante nas entrevistas, nota-se a presença de uma fórmula sugestiva de sonhos e esperanças que os discursos sobre desenvolvimento podem mobilizar, em alguns casos, nessas populações. E como poderia ter algum tipo de efeito mais durável, validando sua importância, se a noção de desenvolvimento não arregimentasse toda uma promessa de segurança, felicidade, bem-estar, um conjunto e categorias de desejos, um modo de vida? Modos de morar, modos de vestir, modos de se comportar. Nas entrevistas, a conceituação de DR não focava apenas bens materiais, tecnologias, acesso a produtos industrializados, como parâmetros de qualidade de vida. De fato, havia uma tendência a escapar a certo economicismo. Nenhuma surpresa, sabendo que, muito mais do que bens, é necessário divulgar formas de vida para uniformizar uma população plural quando refratária a certos 
dispositivos e procedimentos políticos institucionalizados. O engajamento subjetivo se faz mediante fluxos de novas imagens, marketing, informações, serviços diversos, interação com novos sistemas semióticos acessados constantemente (Culler, 1988). Novos sentidos de vida vão sendo incorporados, juntamente com uma estrutura latente de poder, formando subjetividades apropriadas a lógicas de dominação ou emancipação.

Nos processos de contato e interação entre novos saberes e as populações rurais, nem todos conseguem os benefícios conscientemente esperados. Em que pese a discussão acerca das noções de DR proporcionar um auxílio "às tradições rurais", a "modos de vida locais", às redes de pertença e coexistência das pequenas comunidades rurais, muitas vezes este tipo de discurso indica sobejamente como essas redes de vida comunitárias são afirmadas e mediadas pelo lado comercial, pela inserção em uma estrutura socioeconômica ampla, marcada por outros critérios de funcionamento. Nas muitas vezes em que um discurso anti-sistêmico foi evocado, a pregação da "valorização étnica", dos critérios tradicionais de existência no meio rural, com seu peculiar sentido de pertença, sua "proximidade à natureza", sua relativa autonomia, notava-se essa tendência como componente de um contexto semântico e discursivo que não deixava de ser "comercial" quando se punha, por exemplo, o turismo rural como alternativa, principalmente entre os agentes favoráveis ou inclinados à agroecologia ou às "agriculturas alternativas".

No entanto, a parafernália contemporânea de produção de subjetividade não é um caminho de uma só direção. Nas interações, nas lutas, surgem novas modalidades de relações sociais, de trabalho, de formação de sentido e de valorização comunitária, reinvenções de práticas corporais, de solidariedade, de relações de gênero e de gerações. As noções de DR circulantes no campo tecnocientífico em questão tendiam - ao persistirem nos interstícios entre termoschave como "bem-estar", "saúde", "educação", "produção" e "produtividade"-, a considerar a capacidade social de produzir o novo: novas crenças, novas associações, novos desejos, novas 
formas de cooperação, novos padrões produtivos, amparados, na maior parte das vezes, pela ciência, pelas técnicas e tecnologias avançadas e pela indústria.

Uma economia imaterial era formulada. Desenvolvimento ou DR aparecia a partir de uma troca, valorização e circulação de diversos tipos de capitais: econômico, cultural, social, humano, regional, enfim, uma referência às forças vivas presentes em uma rede social. A vida, enquanto fonte e efeito da produção de desejos, crenças, invenção de novos laços sociais, vínculos afetivos, elaboração de associações, vai sendo produzida e reinventada com peculiar vitalidade pelo e para o capitalismo. É onde se configura a consonância de novas tecnologias com uma lógica de poder sobre a vida, produzindo informação, imagens e serviços. O domínio, enquanto desequilíbrio das relações de força, não se faz apenas pela força física, mas mediante uma espécie de "colonização" das sutilezas da imaginação, da produção, da criatividade, da afetividade - gradativamente apropriadas e reelaboradas em seus esquemas cognitivos. A positividade das noções de desenvolvimento percorre perfeitamente esse tipo de exercício de poder que se dá sobre a vida. Os mais variados "capitais sociais" e "simbólicos", enquanto forças de invenção, condensam valor na economia atual.

As promessas e hesitações do desenvolvimento

As metáforas construídas em torno da noção de "desenvolvimento" constituem-se sobre uma infinidade de formas e interesses (Rist, 1996). Os discursos e ações políticas construídos sobre modelos de vida, a ecologia, a biodiversidade, a questão da segurança no campo, a contaminação por agrotóxicos, a poluição são caracterizados como um conjunto simbólico, de um lado tendo a tendência liberal que considera o desenvolvimento como direito de liberdade do indivíduo empreendedor buscar, a seu modo, "uma boa vida", segundo um ideal de modernidade cuja barreira para o poder criativo humano seria a natureza; de outro lado, a formulação de uma ética da vida, "do natural", limitando as possibilidades, diga- 
se, da ciência, na intervenção sobre a vida. Ecologia, ambientalismo, ou toda elaboração metafórica em torno das questões ambientais, da sustentabilidade, da preservação ambiental, das agendas políticas sobre essas temáticas foram constantes nas narrativas sobre desenvolvimento ou DR. Dificilmente se conseguia amarrar coerentemente um ideal de qualidade de vida (a partir do grau de consumo médio de recursos naturais requerido pelo patamar de vida dos países centrais) com um ideal de cuidado ambiental. Esses ideais oscilavam, pois a escolha de um implicava a perda do outro. Era a formação discursiva pautada em um projeto de ciência e sociedade que determinava essa insustentabilidade entre ambiente e acesso a bens e conforto de um padrão civilizatório material.

A mobilização e articulação de uma série de propostas de garantia de proteção e manutenção de dimensões sociais, ambientais, técnicas, entre outras que as noções de desenvolvimento tencionam, estão ligadas talvez aos aspectos multiformes da entrada dos saberes científicos e técnicos no tratamento dado à problemática ambiental, às "tecnologias limpas", à despoluição e à "salvaguarda dos meios naturais", mediante um governo racional dos seres vivos (Lascoumes, 1994). A maioria dos agentes entrevistados ressaltou o papel positivo que a ciência e todo um aparato tecnológico têm para solucionar "os problemas ambientais atuais" decorrentes das técnicas usadas na produção agrícola, ainda que alguns expressassem a inadequação do conhecimento científico para o bem de uma maioria. Quando a problemática do desenvolvimento absorve a temática ambiental, a social, a tecnológica, a científica, enfim, os variados eixos temáticos dispostos no conjunto das "necessidades sociais", a noção de biopoder põe-se como interessante ferramenta conceitual para a análise de algumas facetas do DR.

A manifestação discursiva sobre os temas apresentados como chaves na definição do DR (principalmente saúde, bem-estar e meio ambiente) apresenta uma cumplicidade com práticas sociais mediante a relação verdade/poder. A operação de relacionar, distribuir, regulamentar e produzir enunciados faz parte de uma conexão entre o sistema de poder produtor de "verdades" com os efeitos 
de poder dessas "verdades", que as reforçam e espalham em um determinado período e formação social. De modo geral, os sistemas de conhecimento, com suas verdades, só são compreensíveis quando confrontados com suas regras de produção, guiadas basicamente por sistemas de poder.

Esta discussão sobre os elementos discursivos nas práticas e processos sociais faz-se necessária para se entender o comportamento das relações de poder da sociedade ocidental moderna ligada aos problemas intrínsecos do controle das populações. Até porque muitas das técnicas usadas na sustentação deste "poder moderno" não foram criadas como unidade orgânica, tendo uma finalidade específica de controle entre classes, grupos, pessoas. São técnicas (ou microtécnicas) oportunamente usadas, melhoradas e ampliadas em eficiência, despontadas nas instituições, como escolas, laboratórios, hospitais, casernas, prisões, mosteiros, generalizadas e desenvolvidas por um aparato técnico aperfeiçoável (Foucault, 1977). O teor das falas dos agentes entrevistados reflete a percepção dos sistemas de monitoramento e fiscalização que envolve políticas e ações de DR. Há sempre expectativas de que certas normas e convenções socioculturais ganhem espaço em comunidades ou setores sociais não envolvidos diretamente com sistemas de pensamento e conduta hegemônicos. A expansão desses sistemas se concretiza pelos exercícios de poder sedimentados mediante técnicas de controle adaptadas de acordo com conjunturas históricas, que não desaparecem, mas se sobrepõem e se especializam. Esse conjunto de técnicas exploradas hegemonicamente pelo sistema capitalista não funciona necessariamente de forma negativa. As estratégias e táticas de poder operam produzindo expectativas e necessidades nos sujeitos de acordo com sua lógica de instrumentalização e objetivo da ação. Nota-se um conjunto de questões na problematização do DR - ou da noção de desenvolvimento de forma geral - dentro dessa perspectiva teórica, pois o desenvolvimento, na maioria das vezes, é pensado como separado dos efeitos de poder dos conhecimentos e técnicas gerados no interior das diversas disciplinas dispostas a objetivá-lo em estudos ou realizá-lo em ação (Premebida, 2004). 
A pretensão de relativizar noções de DR gerais e homogêneas tem seu limite na zona constitutiva da própria base discursiva das falas e definições sobre desenvolvimento, embora estas não busquem uma precisão de sentido. Mesmo nas divergências possíveis, a constituição desse discurso está sinalizada como uma adesão comum dessas divergências à idéia de biopoder, resultante de novas relações de poder dispersas na sociedade moderna (intensificada pela tecnociência) e refluindo sobre a prática da gestão das populações. Mesmo com as divergências, existe esta base discursiva compartilhada, na qual o discurso não consegue se evadir, pois constitui o próprio objeto estudado, falado, descrito, realizado pelos agentes, fruto de um "discurso cultural" referendado historicamente e legitimado, principalmente, pelos herdeiros de um saber textualizado em um projeto científico e político ocidental.

\section{Considerações finais}

O debate sobre o avanço técnico na agricultura ou em outras dimensões produtivas e rotineiras da sociedade foi uma das questões mais tratadas nas entrevistas. Se os sentidos de DR e/ou desenvolvimento não destoaram muito em suas linhas gerais, o pouco em que divergiram estava relacionado, principalmente, à divisão de opiniões sobre os usos das técnicas científicas avançadas. Técnicas muito mais extensas do que parcialmente foi indicado aqui na constituição de um repertório de intervenções sobre a vida (biotecnologias), tanto na produção como na reprodução, mediante novos conhecimentos químicos e biológicos em que a informática tem papel de suma importância na virada tecnológica do século XX. Houve, assim, a clássica divisão entre posições favoráveis e desfavoráveis ao projeto de matriz iluminista de esperança no avanço técnico como fundamental para contribuir com o "aperfeiçoamento" ou a "redenção" da humanidade. Muito pelo recorte empírico, a crença no projeto iluminista atravessou, geralmente de forma integral, o discurso sobre o papel da ciência na sociedade, e, ainda que algumas ressalvas tenham sido consideradas, a sua abrangência 
se percebe na crença da possibilidade do domínio da humanidade sobre a natureza, na vantagem e avanço da racionalidade com sua promessa na superação de preconceitos e miséria. $\mathrm{O}$ reino da abundância e das relações harmoniosas na sociedade esteve, nas entrevistas, quase sempre amarrado ao elo entre ciência e técnica.

Houve mais dúvidas e aberturas a questionamentos do que certezas sobre o conjunto temático oferecido pelas questões postas durante as entrevistas, ainda que as linhas gerais da consagração da noção de progresso e da tecnociência tivessem sido preponderantes e indissociáveis. De modo geral, a ciência e a tecnologia são percebidas como fatores fundamentais ao desenvolvimento, e a narrativa do progresso aparece como linha de encadeamento das ações e imagens morais e políticas presentes no discurso sobre o DR. Parece que, com a relativa institucionalização do tema $\mathrm{DR}$, há uma ocasião favorável para se pesquisar a "pressão" da conjuntura histórica referente a demandas sociais na escolha da produção científica sobre as múltiplas dimensões do rural e os aspectos determinantes de sua orientação de pesquisa. Por exemplo, perceber e entender até que ponto o debate ambiental e ecológico, a questão das novas biotecnologias na agricultura e as políticas de segurança alimentar sustentam definições, encaminhamentos e institucionalizações na tentativa de consolidação dessa área de conhecimento.

Sobre a expressão desenvolvimento rural percebeu-se que ainda é pequena a percepção de uma relativa autonomização de áreas de saber ou, o que parece mais certo, uma convergência de disciplinas na constituição de um objeto de estudo. Essa emergência de um campo de estudo está relacionada a uma conjuntura histórica e de decisões políticas, à existência e participação de um grupo de especialistas e às novas orientações teóricas e temáticas iniciadas com o amadurecimento de debates internos e contatos com discussões do exterior.

Ao longo do trabalho, uma questão permaneceu latente, de certo modo clarificando novos caminhos de investigação sobre a temática examinada. Para uma riqueza analítica sobre o tema do 
DR, deve-se tomar em conta um programa de pesquisa centrado em uma "sociologia do conhecimento", levando minimamente em consideração, para a compreensão do funcionamento em um dado momento do campo tecnocientífico, a rede atada estruturalmente sobre as grandes narrativas, as crenças e mitos que dão suporte à elaboração de um projeto de sociedade centrado na ciência, bem como na geração de interesses, nas aspirações pessoais e corporativas, na dinâmica do discurso científico que faz parte das condições sociais de produção da verdade.

\section{Notas}

1 Regularidade discursiva entendida, de forma geral, como referências predominantes e estabilizadas sobre determinados temas, narrativas, explicações e visões de mundo.

2 Ou seja, o conjunto de elementos não-materiais modelados nas relações recíprocas entre as pessoas e utilizados na formação e comunicação das idéias e da representação da realidade em determinados sistemas e contextos sociais.

3 A denominação de campo tecnocientífico enraíza-se no autoreconhecimento dos agentes entrevistados, no seu pertencimento ao mesmo, "extrapolando-se as fronteiras de um campo científico devido à distinção de alguns agentes quanto às possíveis instâncias técnicas e científicas, resultando no seu auto-enquadramento em uma ou em outra. Observa-se que tal distinção vincula-se a uma diferenciação entre extensão e a pesquisa, sendo a primeira, por determinados agentes, considerada uma área técnica e a segunda científica" (Coelho, 2002).

4 O termo tecnociência é emprestado de Latour (2000), caracterizando a combinação de descoberta científica e inovação técnica e, portanto, designando num espaço de poder e sem distinção, as atividades científicas, sociais e técnicas.

5 Nas formas como são orientados, contextualizados e assumidos no interior de outros discursos (interdiscurso).

6 Autonomia que será relativizada pelas condições e particularidades da emergência do "debate científico" brasileiro. Sobre a autonomia do campo científico no Brasil, ver Coradini (1995). 
$7 \mathrm{Ou}$ seja, as idéias e conhecimentos utilizados pelos agentes ou atores sociais nas interações da vida diária estão condicionados (não é um conhecimento tácito), de forma geral, por questões sociais e culturais. Os diversos modos de capitais são adquiridos de forma interativa entre os agentes ao longo da vida.

8 O corpus pode, segundo o fôlego e critérios do pesquisador, ser constituído por todo o universo de enunciados.

9 Todos os docentes entrevistados tinham a pesquisa como parte constante de suas atividades acadêmicas. Por esta razão, a pesquisa estará sempre implícita na indicação desse grupo no quadro dos entrevistados.

10 Pautada atualmente por um forte discurso liberal e daí desobrigando a mediação estatal, enquanto instância pública, no auxílio a populações vulneráveis econômica e socialmente.

11 Não tanto pelo lado disciplinar, mas pelas ações investidas no âmbito populacional.

12 Seguindo parâmetros do corpus, o cerne das propostas de desenvolvimento visa, primordialmente, à melhoria das condições de vida de uma população.

13 "Qualidade de vida", como dito, foi expressão muito enfatizada nas entrevistas como uma das principais metas das políticas de desenvolvimento rural.

14 O termo "capital", ultimamente, tornou-se aglutinador positivo para quase tudo, quando não, e também, para o termo "desenvolvimento".

15 Optou-se aqui por usar "vida" como sinônimo de "mundo da vida" (lebenswelt, no sentido usado por Husserl e depois por Habermas) e como fenômeno biológico stricto sensu. No primeiro caso, mundo cotidiano da experiência humana, anterior a qualquer teorização ou reflexão elaborada. É uma espécie de pressuposto a qualquer tipo de experiência social.

16 Temas e termos que, por sua generalidade e atributos sociais, culturais e políticos arraigados, são inerentemente delicados e dificilmente consensuais. Justamente por isso a relação poder/verdade atua intensamente.

17 Aparecimento de temas, programas de pesquisa e orientações governamentais e não-governamentais sobre este domínio de objetos. 


\title{
Rural development and biopower: reflexions based on the technoscientific field
}

\begin{abstract}
This article analyzes rural development discourses and their approach toward a particular understanding of the exercise of power, based on interviews with agents of the herein called technoscientific field associated with agricultural sciences in southern Brazil. The interface between a theoretical configuration associated with an analytical view of power and the regularity found in rural development discourses leads to the assumption that this common space of sense production and discourse support is closely linked to a wide economic and political strategy (inherent to capitalism) of population management (logic of inclusion). It is also linked to the application of various provisions and technologies in accordance with - and within the limits of - the biopower perspective. In order to infer this relationship, we tried to use the theoretical framework of discourse analysis by means of its simplest method: an examination of the frequency with which key terms are repeated by agents in their expositions on the current rural development debate. This framework helps us to understand an individual's conception, assuming that the individual is coherent and aware of his/her discourse, as well as to perceive the persistence or modification of certain beliefs and myths in the formation of sociological ideals for rural Brazil.
\end{abstract}

Key-words: rural development, technoscientific field, biopower.

\section{Referências bibliográficas}

ALMEIDA, Jalcione. Tecnologia "alternativa" versus tecnologia "moderna": a luta pelo monopólio da competência tecnológica na agricultura. Dissertação (Mestrado em Sociologia Rural) - Universidade Federal do Rio Grande do Sul, Porto Alegre, 1989.

. A construção social de uma nova agricultura: tecnologia agrícola e movimentos sociais no sul do Brasil. Porto Alegre: Editora da UFRGS. 1999.

BAUER, Martin W.; AARTS, Bas. A construção do corpus: um princípio para a coleta de dados qualitativos. In: BAUER, Martin W.; GASKELL, George (Editores). Pesquisa qualitativa com texto, 
imagem e som: um manual prático. Petrópolis (RJ): Vozes, 2002. p. 39-63.

BOURDIEU, Pierre. A economia das trocas simbólicas. São Paulo: Perspectiva, 1974.

. O campo científico. In: ORTIZ, Renato (Org.). Pierre Bourdieu: Sociologia. São Paulo: Ática, 1983. p. 122-155.

COELHO, Vanessa P. Mediadores técnicos, tecnociência na agricultura e a definição legítima da problemática ambiental no campo tecnocientífico. Dissertação (Mestrado em Desenvolvimento Rural) - Universidade Federal do Rio Grande do Sul, Porto Alegre, 2002.

CORADINI, Odaci L. O referencial teórico de Bourdieu e as condições para sua aprendizagem e utilização. Revista Veritas, v. 41, n. 162, p. 207-220, 1995.

CULLER, Jonathan. Framing the sign: criticism and it's institutions. Norman: University of Oklahoma Press, 1988.

DELEUZE, Gilles. Sobre as sociedades de controle. In: sações (1972-1990). Rio de Janeiro: Editora 34, 1992. Conver-

FLICK, Uwe. Uma introdução à pesquisa qualitativa. Porto Alegre: Bookman, 2004.

FOUCAULT, Michel. Vigiar e punir. Petrópolis (RJ): Vozes, 1977. . A vontade de saber. Rio de Janeiro: Edições Graal, 1999. . Em defesa da sociedade. São Paulo: Martins Fontes, 2002.

GNERRE, Maurizzio. Linguagem, escrita e poder. São Paulo: Martins Fontes, 1991.

LASCOUMES, Pierre. L'éco-pouvoir: environnements et politiques. Paris: Éditions La Découverte, 1994.

LATOUR, Bruno. Ciência em ação: como seguir cientistas e engenheiros sociedade afora. São Paulo: Ed. UNESP, 2000.

MAINGUENEAU, Dominique. Novas tendências em análise de discurso. Campinas: Pontes, 1989.

MARRE, Jacques L. História de vida e método biográfico. Cadernos de Sociologia, v. 3, n. 3, p.89-141, 1991.

ORLANDI, P. Eni. Análise de discurso: princípios e procedimentos. Campinas: Pontes, 2002. 
ORLANDI, P. Eni. Interpretação: autoria, leitura e efeitos do trabalho simbólico. Campinas: Pontes, 2004.

PÊCHEUX, Michel. Análise automática do discurso. In: GADET, F.; HAK, T. (Orgs.). Por uma análise automática do discurso: uma introdução à obra de Michel Pêcheux. Campinas (SP): Ed. UNICAMP, 1997. p. 61-161.

PREMEBIDA, Adriano. Desenvolvimento rural e o campo tecnocientifico: a construção de um discurso. Dissertação (Mestrado em Desenvolvimento Rural) - Universidade Federal do Rio Grande do Sul. Porto Alegre, 2004. Disponível em: http://www.ufrgs.br/pgdr/dissertacoes/mestradopgdr/mpgdr_adriano_n036.pdf

RIST, Gilbert. Le développement: histoire d'une croyance occidentale. Paris: Presses de la Fondation Nationale des Sciences Politiques, 1996.

VELHO, Gilberto. Projeto, emoção e orientação em sociedades complexas. In: . Individualismo e cultura: notas para uma antropologia da sociedade contemporânea. Rio de Janeiro: Jorge Zahar, 1999. p.13-37. 